San Jose State University

SJSU ScholarWorks

Master's Theses

Master's Theses and Graduate Research

Spring 2017

\title{
A Feminist Focus Group Analysis of Women's Experiences in Postpartum Yoga Classes with Babies Present
}

Ky Carnell Russell

San Jose State University

Follow this and additional works at: https://scholarworks.sjsu.edu/etd_theses

\section{Recommended Citation}

Russell, Ky Carnell, "A Feminist Focus Group Analysis of Women's Experiences in Postpartum Yoga Classes with Babies Present" (2017). Master's Theses. 4821.

DOI: https://doi.org/10.31979/etd.p8wb-36jp

https://scholarworks.sjsu.edu/etd_theses/4821

This Thesis is brought to you for free and open access by the Master's Theses and Graduate Research at SJSU ScholarWorks. It has been accepted for inclusion in Master's Theses by an authorized administrator of SJSU ScholarWorks. For more information, please contact scholarworks@sjsu.edu. 


\title{
A FEMINIST FOCUS GROUP ANALYSIS OF WOMEN'S EXPERIENCES IN POSTPARTUM YOGA CLASSES WITH BABIES PRESENT
}

\author{
A Thesis \\ Presented to \\ The Faculty of the Department of Kinesiology
}

San José State University

In Partial Fulfillment

of the Requirements for the Degree

Master of Arts

by

Ky Carnell Russell

May 2017 
(C) 2017

Ky Carnell Russell

ALL RIGHTS RESERVED 
The Designated Thesis Committee Approves the Thesis Titled

\author{
A FEMINIST FOCUS GROUP ANALYSIS OF WOMEN'S EXPERIENCES IN \\ POSTPARTUM YOGA CLASSES WITH BABIES PRESENT \\ by \\ Ky Carnell Russell \\ APPROVED FOR THE DEPARTMENT OF KINESIOLOGY \\ SAN JOSÉ STATE UNIVERSITY
}

May 2017

$\begin{array}{ll}\text { Dr. Theodore M. Butryn } & \text { Department of Kinesiology } \\ \text { Dr. Emily H. Wughalter } & \text { Department of Kinesiology } \\ \text { Dr. Matthew A. Masucci } & \text { Department of Kinesiology }\end{array}$ 


\title{
ABSTRACT \\ A FEMINIST FOCUS GROUP ANALYSIS OF WOMEN'S EXPERIENCES IN POSTPARTUM YOGA CLASSES WITH BABIES PRESENT
}

\author{
by Ky Carnell Russell
}

Women in the postpartum period face a number of physical and emotional challenges that research results indicate could be alleviated through exercise. Unfortunately, many new mothers are unable to participate in regular exercise due to a variety of personal and societally constructed obstacles. There is a growing trend to incorporate babies into yoga classes in an effort to increase the accessibility of postpartum exercise. There has been limited research conducted regarding the effectiveness of this emerging trend, and none have examined the feelings of participants engaged in mother and baby yoga classes. To address this gap in the literature, the experiences of 17 new mothers who participated in mother and baby yoga classes were explored. Four focus group semi-structured interviews were conducted utilizing feminist methodology designed to create an egalitarian and empowering experience. A thematic data analysis produced 12 higherorder themes aggregated into four preliminary general categories, including transformation, therapeutic experiences in class, community in class, and mamas' solutions for mamas. Results indicated that mothers relied on these classes to provide physical and emotional healing during their transition to motherhood. Mother and baby yoga classes provided educational, social, and exercise opportunities for the women. The mother and baby yoga classes offered a unique format to provide health and wellness benefits to a potentially vulnerable and underserved population. 


\section{ACKNOWLEDGMENTS}

First and foremost, I thank my committee members for their dedication and expertise. Thank you, Dr. Theodore Butryn, my committee chair, for patient and empowering encouragement throughout that was impressive and inspiring. I also thank Dr. Emily Wughalter for scrupulous attention to detail that challenged me to write meticulously and research rigorously. To Dr. Matthew Masucci, I offer thanks for pep talks and thought provoking questions that forced me to deeply engage in feminist theory and research.

This project was generously funded by the Western Society for the Physical Education of College Women and the Dr. David Furst Scholarship in Sport Studies. The participants were truly touched to hear of this support.

Many thanks to my dear husband, Will, thank you for all of your support and love. You are truly one of the most devout feminists I have ever known. To Trillium, my daughter, this project was born with you and I aspire to be a better person every day because of you. I hope that you never experience a moment of doubt in what you can accomplish in this world. To my mother Linda, thank you. Your ability to resist, and to envision a different reality for me is a shining example of a mother's love.

Last but not least, I give thanks to the beautiful yoga teachers who hold a space for mamas and offer a source of light to the world. And very special thanks to the inspiring mothers who shared their stories. I appreciate your candor and your optimism regarding the world that can be. I truly believe that your support for each other will change the world. Persist. 


\section{TABLE OF CONTENTS}

CHAPTER1: Introduction................................................ 1

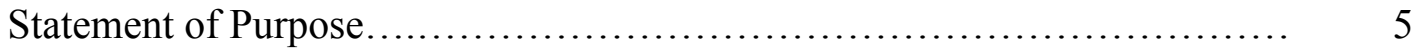

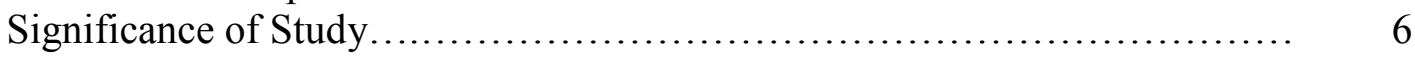

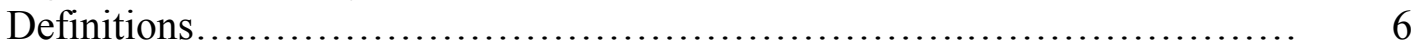

Delimitations...................................................... 7

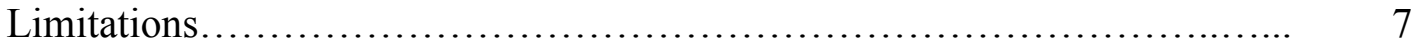

CHAPTER 2: Journal Article..................................................... 8

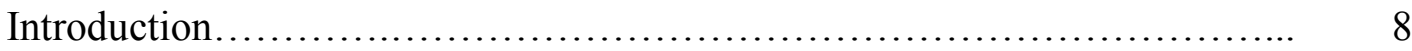

Methods.............................................................. 13

Participants ........................................................ 13

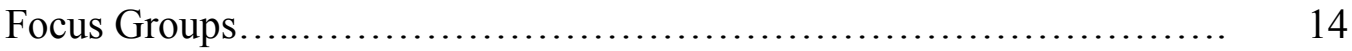

Interview Guide................................................... 16

Bracketing Interview........................................... 16

Data Analysis........................................................ 17

Academic Rigor................................................... 17

Results.............................................................. 18

Transformation.......................................................... 18

Adjustment to Motherhood...................................... 19

New Body................................................. 21

Therapeutic Experiences in Class.................................... 23

Body Healing ................................................ 23

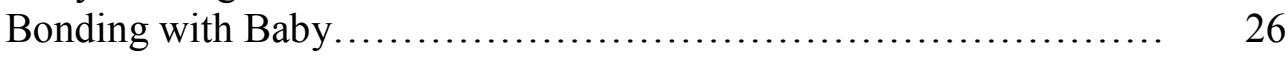

Shifting Exercise Experiences.................................... 27

Community in Class................................................. 29

Safe Space.................................................. 29

Shared Experience................................................ 31

Mothering Resource............................................ 34

Mama's Solutions for Mamas...................................... 35

Sociocultural Attitudes of Mothers.............................. 36

Role Choice....................................................... 37

Feminist Acceptance.............................................. 39

Classes and Educational Support................................ $\quad 40$

Discussion and Conclusions.......................................... 42

References........................................................... 49

CHAPTER 3: Conclusion.................................................... 56

APPENDIX A: THEMATIC DATA ANALYSIS ........................... 58

APPENDIX B: INTERVIEW GUIDE..................................... 61

APPENDIX C: INFOMRED CONSENT FORM............................. 63 


\section{CHAPTER 1: INTRODUCTION}

The following journal article details the experiences of women in postpartum yoga classes with babies present, a growing postpartum exercise trend. Postpartum women are at a high risk of developing a number of serious health complications. Weight retention at six months postpartum can increase the risk of developing obesity and diabetes later in life (Ko, Yang, Fang, Lee, \& Lin, 2013). Levels of severe postpartum depression are found in $10 \%$ to $15 \%$ of postpartum women, and as many as $70 \%$ of women experience mild depressed states known as the "baby blues" (RighettiVeltema, Bousquet, \& Manzano, 2003). Physical and emotional issues that affect new mothers can continue for more than a year following birth and include high levels of pain in the immediate birth-recovery period, increased anxiety, and negative body images (Clark, Skouteris, Wertheim, Paxton, \& Milgrom, 2009; Woolhouse, Perlen, Gartland, \& Brown, 2012). In addition, there are a number of widespread health care policies that have negative impacts on new mothers' health including maternity leave policies, lack of breastfeeding support, and limited access to information (Baker, Choi, Henshaw, \& Tree, 2005; Taylor, 1998).

Exercise during the postpartum period has the potential to benefit the physical and mental health of new mothers (Dritsa, Costa, Dupuis, Lowensteyn, \& Khalifé, 2008; Ko \& Yang, 2008; Larson-Meyer, 2003). The American Council of Obstetricians and Gynecologists (ACOG) recommends that women in the postpartum period engage in 30 minutes of moderate level activity each day (Artal \& O’Toole, 2003). Despite these benefits, many postpartum women do not adhere to ACOG recommended exercise levels 
(Ko \& Yang, 2008, Saligheh, McNamara, \& Rooney, 2016). Lack of time and childcare constraints are the most frequently cited exercise barriers in postpartum populations (Evenson, Herring, \& Wen, 2012; Larson-Meyer, 2003). In addition, there are more complex and systemic issues affecting new mothers' ability and desire to exercise. Physical and emotional issues including fatigue, soreness, incontinence, inability to cope, and feelings of inadequacy in mothering role have also been found to be factors decreasing new mothers' motivation and ability to exercise (Baker et al., 2005; Connolly, Feltz, \& Pivarnik, 2014; Ko \& Yang, 2008; Larson-Meyer, 2003; Saligheh et al., 2016). In addition, limited and vague postpartum exercise guidelines create unnecessary obstacles for new mothers who wish to resume exercising (Artal \& O’Toole, 2003; Larson-Meyer, 2003; Zourladani, Tsaloglidou, Tzetzis, Tsorbatzoudis, \& Matziari, 2011). There is a growing trend to recommend yoga classes to postpartum women in part due to the low-impact nature of the exercises (Ko \& Yang, 2008), yet the effectiveness of yoga has not been widely studied in postpartum populations (Larson-Meyer, 2003). Results from several studies have shown increased quality of life among participants following yoga interventions, and decreased anxiety and better birth outcomes in prenatal women who participated in mind-body programs (Ahearn, 2006; Beddoe \& Lee, 2008; Dillard, 2013; Ko \& Yang, 2008). In a recent study of ethnically diverse postpartum women, Row and colleagues (2013) recommended that further research on yoga classes in postpartum populations be conducted.

Another recommended postpartum exercise trend is the incorporation of babies into the workout (Larson-Meyer, 2003). Exercise programs that include babies may 
increase exercise rates (Jenkins, Handcock, Burrows, \& Hodge, 2006; Ko \& Yang, 2008), and the physical and psychological health of postpartum women improved following an exercise intervention that allowed babies to be present (Cramp \& Bray, 2010; Ko, Yang, Fang, Lee, \& Lin; 2013; Norman, Sherburn, Osborne, \& Galea, 2010). Popular news sources such as the New York Daily News have recently reported that Pilates, yoga, and boot-camp style exercise classes and workout videos that incorporate babies are increasing in number and popularity. Postpartum Pilates and yoga classes are reportedly popular with new mothers because of the convenience of being able to bring their babies, the effectiveness of the workout, the supportive social aspect of being with other new mothers, and the opportunity to bond with their babies (Pesce, 2012).

Yoga is characterized by slow, controlled, low-impact movements (Ahearn, 2006; Ko \& Yang, 2008) that can be adapted to include babies, yet there has been almost no research on yoga classes incorporating babies into the curriculum. In addition, with the exception of research related to exercise barriers (Jenkins et al., 2006; Kieffier, Willis, Arellano, \& Guzman, 2002), almost none of the studies conducted on exercise in postpartum populations have focused on the experiences of new mothers. There is a substantial need to research the experiences of new mothers participating in yoga classes that incorporate babies into class. This type of class has the potential to be well suited to postpartum women and may help facilitate their participation in an exercise program. It is also imperative that research operating within a feminist paradigm be utilized. This type of research has been particularly illuminative in describing the overall experiences 
of postpartum women, yet the exercise experiences of postpartum women have not been explored in this manner (Baker et al., 2005; Clark et al., 2009; Taylor, 1998).

Feminist methodology is particularly suited to researching the experiences of new mothers due to its activist oriented and emancipatory focus (Creswell, 2007). As many of the health policies that impact new mothers have a core of inequity and disenfranchisement (Baker et al., 2005), there is a clear need to research postpartum exercise policies and pedagogy using a feminist framework. Feminism has provided the framework for a wide variety of research topics focused on women's experiences (Beckman, 2014; Eagley \& Rigor, 2014; Olesen, 2017; Taylor, 1998). While there is no consensus on the definition of feminist research, there are a number of commonalities that exist in the literature that help to guide and inform feminist frameworks (Beckman, 2014; Hesse-Biber, 2014; Olesen, 2017; Taylor, 1998). Beckman (2014) described feminist research as it relates to methodology, or the underlying set of beliefs that guides the research choices, as opposed to the use of any particular method. Through a review of feminist literature, she outlined equality and egalitarianism for women and men as the basic tenets informing feminist research. This is echoed by Taylor (1998) who stated, "Ultimately feminist methodology aims to outline an approach to research consistent with feminist aims of challenging gender inequality and empowering women" (Taylor, 1998, p. 358). Any study that intends to examine the experiences of women during the postpartum period will benefit from a feminist framework, as much of the reality of the postpartum period is influenced by inadequate social and medical care that stems from 
gender inequality (Baker et al., 2005; Choi, Henshaw, Baker, \& Tree, 2005; Taylor, 1998).

Focus group interviews are frequently utilized in feminist based research, (O’Shaughnessy \& Krogman, 2012) and are particularly well-suited to research with postpartum participants. Focus group interviews can lead to a more egalitarian relationship between participants and the researcher, create a positive environment that can bring change to the lives of participants, and enable participants to engage and connect with other women in similar situations (Kamberelis, Dimitriadis, \& Welker, 2017; Montell, 1999; Munday, 2014; Smith \& Sparkes, 2014). Previous research has utilized focus groups interviews to explore the experiences of breast cancer survivors in yoga classes (Van Puymbroeck, Burk, Shinew, Kuhlenschmidt, Schmid; 2011). The researchers reported that the group interview experience was particularly beneficial in discussing how the group members felt while exercising in a group setting (Van Puymbroeck et al., 2011). There have currently been no studies that have sought to explore the experiences of postpartum women in yoga classes with babies present utilizing a feminist framework.

\section{Statement of Purpose}

This study's purpose was to examine the experiences of new mothers during postpartum yoga classes with babies present utilizing focus group interviews in order to more fully understand the appeal and benefits of the classes and provide a beneficial group sharing experience for the participants. 


\section{Significance of Study}

This inquiry highlighted the physical and emotional benefits of postpartum yoga classes to potentially inform postpartum exercise pedagogy and promotion. This study added to the literature on women's postpartum experiences, and shed light on sociocultural and medical policies that do not address and service the substantial needs of postpartum women. Finally, results from the thematic data analysis (Appendix A) offered the possibility that mommy and me yoga classes may offer a unique form of institutionalized social support for postpartum women.

\section{Definitions}

The following definitions garnered from the literature review were used to guide the study.

Postpartum. The postpartum period was defined as the time from delivery until the baby reached crawling age, as crawling babies are no longer eligible to attend class with their mothers. This is consistent with definitions given in the literature, as studies label the postpartum period from six weeks to as long as a year after delivery date (Armitage \& Smart, 2012; Jeffreys \& Nordahl, 2002).

Yoga. Yoga is a wellness system that was developed in India thousands of years ago. There are eight "limbs" of yoga that address physical and psychological health including postures, breathing, meditation, concentration, and self-enlightenment (Delaney \& Anthis, 2010). 


\section{Delimitations}

Delimitations for this study included the use of a semi-structured interview guide consisting of ten questions and associated probes (Appendix B). The selection of questions prioritized the participants' experiences in the yoga classes and in the postpartum time period (Smith \& Sparkes, 2014). The questions also encouraged a conversation style approach to the interview that is consistent with previous feminist focus group research (Aston, 2002; Baker et al., 2005; Choi et al., 2005; Clark et al., 2009; Spiteri \& Xuereb, 2012).

Participants were delimited to women who self-reported attendance in mother and baby yoga classes within the previous three years.

\section{Limitations}

There were several limitations regarding the participants. Most notably, the majority of the participants were well-educated, heterosexual, White, middle-class women who may have had access to services, experiences, and medical care that women from other socio-economic and ethnic backgrounds did not. The participants also resided within the same county in coastal CA. Their experiences may have been influenced by community factors that do not exist elsewhere. For some of the participants the interviews were retrospective. Therefore, there may have been some details that they could not recall. Their perceptions regarding their past experiences could have also been influenced by recent events. 


\section{CHAPTER 2: JOURNAL ARTICLE}

\section{Introduction}

The postpartum period can be a time of conflicting experiences as women adjust to the demands of new motherhood and recover from the intense physical experience of pregnancy and birth (Aston, 2002). Physical complications including exhaustion, painful perineum, breast problems, dizziness, hemorrhoids, and back pain can persist for up to a year or longer following delivery (Gjerdingen, Froberg, Chaloner, \& McGovern, 1993; Woolhouse, Perlen, Gartland, \& Brown, 2012). Up to $70 \%$ of postpartum women experience the "baby blues," a temporary mood dysphoria that usually occurs within the first weeks of the postpartum period and is characterized by crying and extreme emotional states (Armstrong \& Edwards, 2004). Postpartum depression impacts 10-15\% of postpartum women (Righetti-Veltema, Bousquet, \& Manzano, 2003). Other emotional complications include anxiety, body dissatisfaction, family stress, challenge adjusting to the motherhood role, loss of self, and stress related to medical and social structures that tend to prioritize the needs of the baby over the experiences of the mother (Aston, 2002; Baker, Choi, Henshaw, \& Tree, 2005; Clark, Skouteris, Wertheim, Paxton, \& Milgrom, 2009). In addition, results of previous research indicate sociocultural policies including lack of adequate maternity leave, lack of support regarding breastfeeding, lack of mothering resources, and lack of postpartum medical care adversely affect new mothers (Aston, 2002; Baker et al., 2005; Buurman \& Lagro-Janssen, 2013; Row, Nevill, Bellingham-Young, Adamson-Macedo, 2013; Taylor, 1998). Despite these health risks, many women receive little social support or medical guidance during the postpartum 
period (Aston, 2002; Baker et al., 2005; Buurman \& Lagro-Janssen, 2013; Row et al., 2013).

Exercise in the postpartum period may reduce depression levels, fatigue, and physical discomfort, yet postpartum women are at high risk for low physical activity levels (Dritsa, Da Costa, Dupuis, Lowensteyn, \& Khalifé, 2008; Ko \& Yang, 2008; Larson-Meyer, 2003; Zourladani, Tsaloglidou, Tzetzis, Tsorbatzoudis, \& Matziari, 2011). Exercise barriers in postpartum populations include personal and sociocultural factors, such as lack of time, childcare duties, lack of confidence, lack of information regarding exercise, fatigue, and discomfort (Connolly, Feltz, \& Pivarnik, 2014; Ko \& Yang, 2008; Larson-Meyer, 2003; Saligheh, McNamara, \& Rooney, 2016). Researchers have also found that new mothers reported feeling guilty when choosing exercise over household duties and frequently prioritized family duties over their own health, which negatively affected their exercise adherence levels (Jenkins, Handcock, Burrows, \& Hodge, 2006; Keiffer, Willis, Arellano, \& Guzman, 2002).

Research findings indicate that social support is an exercise enabler (Connelly et al., 2014), and a qualitative study found that new mothers believed social support was important to their ability to fulfill basic care needs and avoid elevated levels of depression (Negron, Martin, Almog, Balbierz, \& Howell, 2013). Research results on postpartum exercise barriers highlighted the potential of group class settings to provide social support to new mothers as a mechanism to encourage exercise (Saligheh et al., 2016), yet the ability of group exercise classes to provide social support around the act of motherhood has not been thoroughly studied. In a related study, Aston (2002) found that 
the effectiveness of non-exercise based postpartum support groups varied according to type and setting of the group.

Studies have also shown that postpartum women are more likely to participate and adhere to an exercise regime if they perceive it as appropriate and specifically designed for postpartum women, highlighting the need for women-centered accessible exercise programs for postpartum populations (Jenkins et al., 2006; Keiffer et al., 2002). Despite research findings that yoga is frequently recommended for postpartum women (Ko, Yang, Fang, Lee, \& Lin, 2013; Swanson, 2001), the effectiveness of yoga has not been widely studied in postpartum populations (Ko \& Yang, 2008). There is some evidence that mind-body meditation interventions helped to decrease anxiety in pregnant women resulting in better birth outcomes (Beddoe \& Lee, 2008), and cancer survivors reported physical, social, and mental health improvements from yoga classes (Uden-Kraan, Chinapaw, Drossaert, Verdonck-de Leeuw, \& Buffart, 2013; Van Puymbroeck, Burk, Shinew, Kuhlenschmidt, \& Schmid, 2011). Similar to research findings on exercise barriers in postpartum populations (Row et al., 2013), Uden-Kraan et al. (2013) found cancer survivors desired specific and tailored programming to begin exercising following treatment. Researchers found that postpartum women repeatedly stated that they felt confused and unsure about exercising in the postpartum period and desired specific exercise programming for the postpartum period (Connelly et al., 2014; Jenkins et al., 2006).

Since the lack of childcare and emotional concerns over prioritizing their own needs are believed to be the most prevalent exercise barriers to postpartum populations, 
there is a growing trend to include babies in postpartum exercise routines (Larson-Meyer, 2003; Pesce, 2012). Several research studies have shown that including babies in exercise can be useful in encouraging new mothers to exercise (Jenkins et al., 2006; Ko \& Yang, 2008; Saligheh et al. 2016) and improving psychological health (Cramp \& Bray, 2010; Norman, Sherburn, Osborne, \& Galea, 2010).

Yoga is a mind-body exercise system characterized by slow, controlled movements and low-impact exercises (Ahearn, 2006; Ko, \& Yang, 2008) that can be adapted to include babies, yet there has been almost no research on incorporating babies into yoga curriculum. In addition, with the exception of research related to exercise barriers (Jenkins et al., 2006; Kieffier, et al., 2002; Saligheh et al., 2016), almost none of the studies conducted on exercise in postpartum populations have focused on the experiences of new mothers. Thus, there is a clear need to examine the experiences of new mothers participating in yoga classes that incorporate babies into the class. This type of class has the potential to be well suited to postpartum women and may help facilitate their participation in an exercise program.

Feminist research has been the foundation of a number of studies focusing on postpartum populations as many of the realities of motherhood are connected to systemic and socially constructed gender inequities (Baker et al., 2005, Choi, Henshaw, Baker, \& Tree, 2005; Taylor, 1998). While there is no consensus or singular definition of feminist research, there are a number of researchers who have described feminist research as research that explores power imbalances and cultural values that lead to gender inequity, prioritizes women's stories, has researcher reflexivity, empowers participants throughout 
the research process, and utilizes the research results in an activist oriented manner that aims to impact the lives of women (Beckman, 2014; DeVault, 2017; Hesse-Biber, 2014; Harding, 1987; Lather, 1991; O’Shaughnessy \& Krogman, 2012; Reinharz, 1992, Taylor, 1998). Olesen states that "The hope is for, if not emancipation, at least modest intervention and transformation without replicating oppression" (2017, p. 163).

Focus groups are well-suited to feminist research that aims to highlight the experiences of women, enable women to share and engage with other women, and create a more egalitarian research setting that can lead to more revealing information and empowerment (Kitzinger, 1994; Lather, 1991; Montell, 1999; Munday, 2014). Focus group research has also been used in a number of studies examining the experiences of cancer survivors in yoga classes, and in a study on the experiences of ethnically diverse postpartum women (Uden-Kraan et al., 2013; Van Puymbroeck et al., 2011; Row et al., 2013). Few studies have examined a broad range of women's postpartum exercise experiences in a qualitative manner (Saligheh et al., 2016). Van Puymbroeck et al. (2011) utilized focus groups as a research tool to examine the experiences of women in yoga classes following breast cancer treatment. The researchers theorized that a group interview setting better allowed participants to share the experiences of participating in group exercise classes, leading to a better understanding of the phenomenon being studied (Van Puymbroeck et al., 2011). As there has been little research on exercise in postpartum populations from a feminist framework utilizing focus group methods, the aim of the current study was to identify and contextualize women's experiences in 
postpartum yoga classes with babies present in an effort to create meaningful change in the lives of postpartum women.

\section{Methods}

\section{Participants}

Following Institutional Review Board approval, participants $(N=17)$ were contacted through two local yoga studios that offered postpartum "mommy and baby" yoga classes. Criteria for inclusion in the study were (a) being a mother of at least one child (b) self-identification as having attended "mommy and me" yoga classes regularly during the postpartum period and (c) attendance in postpartum classes with babies that occurred no more than 3 years prior to the interview. The postpartum period was defined for this study as the time from delivery until baby reached crawling age, as crawling babies are no longer eligible to attend mother and baby yoga class with their mothers. This is consistent with definitions given in the literature, as studies label the postpartum period from 6 weeks to as long as a year after delivery date (Armitage \& Smart, 2012; Jeffreys \& Nordahl, 2002). No other delimitations (such as race, socioeconomic status, or ethnicity) were used to select participants for several reasons. Despite a growing body of feminist intersectionality research that seeks to highlight the experiences of women outside the White, heterosexual, middle-class dominant culture (Beckman, 2014; Olesen, 2017), the study of a broad and diverse group of mothers who had a common experience of participating in postpartum group yoga classes has not been well studied. The broad range of participants in this study ensured that there were enough participants for the study, allowed for a multidimensional examination of the situated experiences of 
participants, and provided for a range of divergent viewpoints regarding the mother and baby yoga classes (Oleson, 2017).

Participants ranged in age from 25 to 42 years $(M=34)$ and were 8 weeks to 4 years postpartum. Participants came from a variety of ethnic backgrounds and identified as White $(\mathrm{n}=12)$, Latina $(\mathrm{n}=2)$, Native American and White $(\mathrm{n}=2)$ and Asian American $(n=1)$. Participants were all in heterosexual relationships residing with a male partner during their postpartum period, yet one woman was single at the time of the interview. Participants were well educated with eight women possessing bachelor's degrees, seven with master's degrees, and two with some college or vocational training. All of the participants reported being employed prior to having a child, three identified as being on maternity leave, and the remainder were unemployed or employed part time. Participants reported a variety of household incomes ranging from less than $\$ 35,000$ per year $(n=1)$, $\$ 35,000-\$ 75,000$ per year $(n=9), \$ 75,000-\$ 150,000$ per year $(n=4)$ and higher than $\$ 150,000$ per year $(n=3)$.

\section{Focus Groups}

A total of four focus group interviews were conducted after obtaining IRB approval and informed consent, ranging in size from four to five participants. This sample size is consistent with previous feminist and sport and exercise research utilizing group interviews (Aston, 2002; Clark et al., 2009; johnson, Butryn, \& Masucci, 2013; Smith \& Sparkes, 2014).

Semi-structured focus group interviews are commonly used in both health services and feminist research, and have provided information about individuals' 
experiences specifically in regards to socially constructed gender inequities (Kitzinger, 1994; O’Shaughnessy \& Krogman, 2012; Montell, 1999; Smith \& Sparkes, 2014; Taylor, 1998). Focus groups are well-suited to feminist research that aims to highlight the experiences of women, enable women to share and engage with other women, and create a more egalitarian research setting that can lead to more revealing information and empowerment (Kitzinger, 1994; Munday, 2014; Montell, 1999). In addition, focus groups were utilized due to the desire to provide an enriching experience that could potentially bring awareness and emancipation to participants.

Interviews were held at one of the yoga studios where the mother and baby classes occurred. The participants were familiar with the location, which helped to create a comfortable interview environment and potentially deconstructed feelings of power inequity between the interviewer and interviewees (Berg, 2004; Clark et al., 2009). As is common recommended practice in focus group interviews, participants were arranged in a circle to encourage group interaction and lessen research hierarchy (johnson, et al., 2013; Kitzinger, 1994; Montell, 1998). Following previous interview protocols for postpartum populations, mothers either brought their babies to the interview or childcare assistance was provided, and participants were offered a multitude of days and times that allowed each participant to choose a group time that was convenient (Choi et al., 2005). The interviews were video and audio recorded, and were transcribed verbatim with all identifying information changed to protect identities. Data collection continued until data saturation was reached. 


\section{Interview Guide}

The interview guide consisted of ten questions designed to encourage the participants to discuss their experiences in the yoga classes with babies, their relationship with their body during the postpartum period, the role of exercise in their lives as new mothers, and their overall experiences with motherhood. The questions were also intended to create ease among the participants and lead to free information exchange, consistent with previous feminist research (Aston, 2002; Baker et al., 2005; Choi et al., 2005; Clark et al., 2009; Spiteri \& Xuereb, 2012). Each interview began with a silent icebreaker activity that prompted participants to reflect on their associations with the postpartum time period. Participants were also given an opportunity to provide any additional information that they felt was relevant and provide feedback about the interview process (Smith \& Sparkes, 2014).

\section{Bracketing Interview}

While bracketing interviews are usually recommended solely in

phenomenological research, I had a background that closely connected me to the research participants so that it was useful to participate in a bracketing interview before data collection and analysis (Dale, 1996). A researcher with extensive interviewing experience administered the interview guide to help me explore and acknowledge my assumptions and biases. This helped to establish academic rigor and refined the interview guide, and served as a self-reflexivity practice that is critical to feminist research (Eagly \& Riger, 2014). 


\section{Data Analysis}

An inductive thematic analysis was conducted on transcripts throughout the study. Following guidelines from Gratton and Jones (2004), data were coded into 93 distinct raw data codes. The patterns in these themes were located and connected into 12 higher order themes, and again into four general categories. This analysis was consistent with numerous feminist research studies in postpartum populations (Aston, 2002; Baker et al., 2005; Choi et al., 2005; Clark et al., 2009; Spiteri \& Xuereb, 2012).

\section{Academic Rigor}

Qualitative research, especially feminist research, acknowledges that experiences are constructed and knowledge is situated within complex social spheres that reject positivist assumptions that there is an objective truth (Beckman, 2014; Smith \& Sparks, 2014). Yet there is a need to maintain academic rigor that is established through systematic procedures that can expose the beliefs and biases of the researcher, thereby allowing the information gained through the research study to be examined through appropriate lenses (Berg, 2004). Academic rigor in this study was accomplished through several protocols including a bracketing interview, peer review of data analysis that included several meetings and email exchanges with an expert qualitative researcher who had read and provided extensive feedback for each transcript, and the maintenance of a self-reflexivity journal (Dale, 1996; Miyaka \& Kai, 2009; Smith \& Sparks, 2014). As a feminist mother of a young child, I experienced firsthand how mother and baby yoga classes could help to navigate the rough waters of new motherhood. The keeping of a self-reflexivity journal proved to be a valuable tool that helped me examine my own 
thoughts and feelings regarding the project and acknowledge my biases and assumptions regarding the postpartum time period, feminism, and mother and baby yoga classes.

\section{Results}

Thematic analysis of the focus group interview data produced four overarching interconnected categories, each of which contained multiple themes. The women described the process of becoming a mother as a transformative event that impacted nearly every aspect of their lives. The significance of the mother and baby yoga classes can only be understood when viewed through the lens of this metamorphosis. The women felt that the classes provided therapeutic benefits for their minds and bodies, as well as opportunities to connect with a network of mothers in their community. The mothers also envisioned sociocultural, personal, institutional, and medical policies that could improve the lives of postpartum women. The four major categories, (1) transformation, (2) therapeutic experiences in class, (3) community in class, and (4) mamas' solutions for mamas are discussed below, in addition to the most relevant themes in each category.

\section{Transformation}

The view of motherhood as a transformative act was pervasive throughout the interviews, something that was consistent with previous research findings related to women's experiences of motherhood (Aston, 2002; Baker et al., 2005, Saligheh et al., 2016; Tugut, Tirkes, \& Demeril, 2015). All of the participants stated that having a child was a life-changing experience with extreme corporeal and emotional effects. Their feelings regarding the mother and baby yoga classes were intimately connected to the 
process of this transformation. The category of transformation and the associated major themes of adjustment to motherhood and new body are discussed below.

Adjustment to Motherhood. All of the participants noted challenges associated with the adjustment to motherhood while conveying that their overall transition was empowering and positive. Many of the mothers discussed feeling overwhelmed that they were the primary caregiver for their babies, and surprised at the focus on the mother and baby relationship in the early postpartum months. Similar to previous research findings (Liss \& Erchull, 2012; Salee, 2007), many of the participants believed breastfeeding contributed to their role as primary caregiver, resulting in gender based work and power imbalances within the domestic sphere and negative health outcomes. Participants described a loss of independence associated with breastfeeding that prohibited them from leaving their babies or participating in other activities, especially exercise.

In addition, none of the mothers felt adequately prepared for what one mother stated was "an extreme bond for her baby," that resulted in many of the women feeling anxious or unwilling to leave their babies, even when family members could provide childcare. Mothers of younger babies discussed feeling constantly worried and concerned about their children, which intensified when they were apart. Most had not attempted to regularly exercise without their baby during the first year of the postpartum period. One mother described what occurred when she left her child to attend a yoga class:

He was refusing to take a bottle even though it was breast milk. So ... I'm in shavasana and I'm supposed to be totally blissed out and all I can think about is just my child is at home screaming and won't take his bottle from his papa. 
Mothers' reluctance to leave their babies to exercise even when childcare was available is not widely acknowledged in previous research findings on postpartum exercise barriers, potentially indicating that it is not just lack of childcare but some women's desire to be with their children that negatively impacts their ability to exercise. In addition, the high levels of anxiety that mothers described potentially negated the benefits of time away from their babies.

For many of the women the adjustment to motherhood included increased domestic duties while they were adjusting to stressful childcare responsibilities. Similar to findings on postpartum women's exercise adherence, the results of the focus groups indicated that the predominance of the motherhood role and increased household duties contributed to many of the women prioritizing others' needs before their own, leaving them with little time to care for themselves, exercise, or fulfill other basic needs (Bellows-Riecken \& Rhodes, 2008). As one participant described her feelings while being on extended maternity leave:

There's that whole change in dynamic, as well. It's like he's supporting us financially and it's like I feel I have to do so much work, it's like earn my keep, which is so stupid. But I don't know. I don't think he gets how much difficult work it is. Even though he tries and is super understanding, it's just if you're not doing it you don't understand it.

Most of the women agreed feeling like they should assume more household duties to offset their loss of income. This was often conveyed as an internalized pressure instead of something driven by their partners, yet the effect was detrimental to their ability to exercise or engage in leisure activities. In a review study of literature on mothers' physical activity levels conducted by Bellows-Riecken and Rhodes (2008), 
household duties increased for most women following childbirth, resulting in a substantial decrease in exercise levels when compared to women without children. Certainly most of the mothers interviewed described this process, which was often a surprising and unintended component of their transformation to motherhood.

New Body. The women in the focus groups described feeling that their bodies, as well as their lives, had been transformed through pregnancy, birth, and the postpartum period. They explained that they experienced new discomforts in the postpartum period, while many were still recovering from physical problems encountered during pregnancy and birth. All of the women had carried their own children, and as a result experienced significant corporeal changes such as feeling like they had a whole new body. For many, the feeling of their new body equated to a feeling of that they had a new identity as well.

There were varying and sometimes conflicting views held by individuals regarding their body image. The women expressed feeling challenged or "resentful" by the concept of their new body, even while many of them expressed empowerment and pride over the work their new body had accomplished. One mother described:

For me I have these two very opposing views of my body now. I'm so proud that it somehow produced a new human being and that I can make milk and sustain this human being with my body. That's incredible. It's empowering to have gone through the process of birth. I'm sure that most of you share that opinion. But then there's also this feeling of resentment. Well okay, now that you've done that, can we go back to what we had before.

The linkage of high body functionality perception with increased body satisfaction in pregnant women was found by Rubin and Steinberg (2011). Yet the women in this study only partially supported the idea, instead many of them described feeling they should 
embrace the changes in their bodies because it related to the process of becoming a mother. One mother explained, "I think the weight gain has actually been hard for me. Even though I hate to say that because it's beautiful and wonderful and all that but it's an identity change. It's just weird and different."

Several of the mothers expressed feeling distrust with their new bodies, particularly those who experienced difficult pregnancies or births. Many of the women were not prepared for the myriad physical problems experienced during the postpartum period, which included pelvic floor pain, back pain, upper body discomfort, lack of sleep, and pain during intercourse. These challenges were intensified due to the lengthy time of recovery, which was surprising for some of the women. Most of the participants described that their bodies felt out of control, or as several women described feeling a "loss of ownership" over their bodies that began in pregnancy and extended into the postpartum period.

The feeling of having an uncontrollable new body influenced the women's sentiments regarding exercise in the postpartum period. An exchange by two mothers illustrated how their new bodies affected their activities:

P1: Your whole idea of what you like to do and what you can do, it's just gone and you have to start over.

P2: When you were saying starting over. It's almost like you have a different base now. You're not as strong as you used to be. You're not as flexible as you used to be. You have a new body. It's the same but it's different.

The mothers consistently felt that their new postpartum body required a new approach to exercise that was an unexpected component of their postpartum reality. They indicated 
that they sought out the mother and baby yoga classes in part because they were unsure of how to manage and restore their postpartum bodies and they felt the classes were designed for their needs. This is similar to results from previous studies that indicated specific programming for postpartum women may enable exercise participation in postpartum populations (Evenson, Aytur, \& Borodulin, 2010; Jenkins et al., 2006; Keiffer et al., 2002; Saligheh et al., 2016).

\section{Therapeutic Experiences in Class}

The second major category involved the therapeutic experiences in the mother and baby yoga classes. The women felt the classes were a unique opportunity to connect with their postpartum bodies and their babies. All of the mothers interviewed indicated that the mother and baby yoga classes were a source of physical and emotional healing during their postpartum period. They looked to the classes for recovery more than exercise; their therapeutic experiences in the classes are discussed through the themes of body healing, bonding with baby, and shifting exercise experiences.

Body Healing. Nearly all of the participants spoke about the mother and baby yoga classes as a vehicle for physical recovery from the bodily pain and discomfort associated with their new bodies. One participant described:

My body was in really rough shape. It took me a long time to heal. Just being able to get there and do yoga ... I remember even just the first couple months I was going to it, I could hardly do anything and they were still just so supportive and so helpful and it was awesome. It really helped me to heal and then be able to kind of move on and start doing other kinds of exercises.

In all of the groups the mothers expressed confidence that they were receiving instruction specifically tailored to their needs in the mother and baby yoga classes due to 
the focus on safely strengthening the core and upper body, which lead to feelings of physical safety and reassurance and potentially encouraged participation. It is well established in the literature that postpartum women are more likely to exercise when they believe they are engaging in activities that are designed for postpartum women's needs (Connolly et al., 2014; Evenson et al., 2010; Ko \& Yang, 2008; Saligheh et al., 2016), which the participants universally believed was true of the mother and baby yoga classes.

Exercise is recommended in the postpartum period by the American College of Obstetricians and Gynecologists (ACOG) without standardized recommendations as to the type, level, and amount of exercise in postpartum populations (Artal \& O'Toole, 2003; Evenson, Mottola, Owe, Rousham, \& Brown, 2014; Larson-Meyer, 2003), which can exacerbate feelings of confusion and uncertainty among postpartum women (Connelly et al., 2014; Jenkins et al., 2006). Mothers frequently discussed feeling uncertain regarding exercise, but felt reassured during the classes. A participant who experienced diastasis recti, a separation of the rectus abdominal muscle sheath, looked to her teacher for information and guidance in how to safely work with her new body, which her medical doctor did not provide:

And they taught me these are the movements that are safe for you to do, these are the ones that are not safe for you to do, and before that I had no idea and was thinking like, "Oh, I should start doing crunches," when really that's the worst thing you can do.

Many of the mothers described situations where their yoga teacher addressed concerns regarding the functioning of their postpartum body that they did not receive elsewhere. These results are similar to findings from a study by Martin and colleagues (2014) that indicated postpartum women felt they received inadequate preparation and medical care 
for a variety of postpartum health concerns. It has not been previously mentioned in the literature that women may look to exercise related classes as a way to fill the gap in care they receive.

The mothers described that the slow and gentle pace of the classes gave them an opportunity to reconnect and regain control of their bodies. The benefits of this reconnection were considered vitally important to most of the participants; many of whom viewed lactation as an ongoing component of the loss of control of their body. The mothers felt the classes helped to alleviate the physical discomforts associated with nursing, which potentially empowered them in regards to their own bodies. Brown and colleagues (2015) demonstrated that mothers who ceased breastfeeding due to pain and difficulty were more likely to experience postpartum depression than mothers who ceased breastfeeding due to other considerations, such as convenience. Several of the mothers described support and instruction they received in the classes on proper breastfeeding postures which they believed helped them to breastfeed. One mother shared how the class helped her deal with the experience of breastfeeding:

What we were talking about before, losing your body, lack of control over your body and giving your entire body to your baby. You get a moment in the postnatal yoga class, even if it's only a short time where you're focusing on yourself, but I feel like when we're in all those nursing postures, we're not even thinking about the pain we're experiencing. Then when you're in yoga, you're really conscious of like, "Oh, I gotta pull my shoulders back." Just being in your body, it's reconnecting to your body. In yoga, you're getting back to remembering that you can have control over your feelings in your body again.

These findings are consistent with the results of previous studies that determined cancer survivors felt yoga was a useful mechanism for regaining awareness and control 
over their bodies (Uden-Kraan et al., 2013; van Puymbroeck et al., 2011). The nuanced and subtle nature of much of the work in yoga lends itself particularly well to this phenomenon, as students are instructed to focus on the process of the class instead of an end product. Yet the impact of yoga in postpartum populations has not been previously studied.

Bonding with Baby. In addition to convenience, the opportunity to bring babies to the classes provided mothers with an anxiety-free experience that many of the mothers felt contributed to the healing nature of the classes. The mothers also described how they learned to be comfortable exercising with their babies. One participant stated, "To realize that you can actually take care of your body even while you're holding this baby and even how to just incorporate them into stretches and movement. That's a huge thing."

The participants were in consensus that a particularly worthwhile component of the classes involved time to play with their babies. In almost every class, the teachers would lead the mothers in a combination of baby massage, gentle activities for the baby, and songs. Previous research findings have shown that massage of preterm infants has been linked to a decrease in mothers' state anxiety (Afand, Keshavarz, Fatemi, \& Montazeri, 2016). Many of the participants described how this play time helped them learn new ways to physically interact with their babies, and others described how it was unique time in their schedule when they could focus on their babies. An exchange from one group highlighted this phenomenon:

P1: There's some bonding about it. To even just go someplace with the intention of doing yoga together and there's nothing else you're doing. You're not worrying about the dishes, you're not worrying about what you're not getting done at home. It's like this sweet 
little moment in time that you've carved out to be together and I think that has value in itself.

P2: $\quad$ Yeah I can totally relate to being able to be more present with yourself and with your baby in classes where you're not distracted by everything. I did feel I should be doing this or I should be doing that at home constantly because there is actually more to do then. And like the expectations that I had for myself but that I feel like our society has for us as mothers is not realistic.

The idea that household duties and other responsibilities took priority over women's selfcare has been well documented in the literature, (Baker et al., 2005; Choi et al., 2005; Connelly et al., 2014). However, the negative impacts of these duties on mother and child bonding has not been well researched. Yet it was clear many of the women felt that the time to connect with their baby in yoga class was unique and uninterrupted. This contrasted with their experiences of being at home with their baby where they had other responsibilities which superseded playing and potentially bonding with their babies.

Shifting Exercise Experiences. The therapeutic experiences in the yoga classes related to the mothers' perceptions about the classes as a form of exercise. Many of the women viewed the classes as an opportunity to focus on doing something beneficial for themselves which was an anomaly in their daily routine:

From the very first time that I came, when I got home I told my husband that it's the most therapeutic thing I've done for myself since giving birth. It was this wonderful opportunity to tend to the aches and pains that we ignore during the process of mothering and connect our minds and bodies in a way that I didn't have an opportunity to do since giving birth.

These positive feelings stand in contrast to the struggles that the women described as part of their adjustment to motherhood. There are also prevalent findings throughout the literature that show there is a tendency among families, medical establishments, and even 
mothers themselves to disregard mothers' health and well-being (Aston, 2002; Baker et al., 2005; Choi et al., 2005). The women interviewed shared this view, and described the mother and yoga baby classes as something uniquely designed to meet their needs, which is lacking in sociocultural institutions and postpartum policies.

However, a few of the participants expressed contradictory viewpoints of the classes. Some women discussed that they absolutely needed a slow and deliberate pace to feel safe while exercising, yet others stated the classes were not "real exercise." Many of the women held both viewpoints simultaneously, describing scenarios where they sometimes were frustrated by the classes:

Sometimes it would feel frustrating in the beginning, especially when I wasn't used to it. When I got more accustomed to doing it with her it felt good. It felt good to be able to stretch and strengthen my body and sometimes it felt really playful too. But I definitely needed the support of a class structure to be able to do it most of the time because it's hard to do yoga with a baby. So it's good and hard.

There was an anecdotal association between the women's self-described efficacy at practicing yoga and feelings that class was not rigorous. There were also mothers who had not previously practiced yoga who felt class was sometimes too slow, or expressed frustration at not being able to exercise throughout the class to address their babies' needs. One mother described how she managed her expectations to help alleviate potential frustrations of the class:

I found I had to be careful how much I depended on them for actual exercise because there were some days I really got to do yoga and there were some days I spent the whole class sitting there breastfeeding. I had to be careful. Those classes meant more than just exercise because it was getting together, it was getting out of the house, getting together with other moms, that all made up for the fact that some days I didn't really get to do yoga. 
The tendency to view the totality of the benefits of the class instead of focusing on exercise was widespread among the participants. Yet there were mothers who felt more strongly that their babies were a distraction that prevented them from focusing on their own needs during the classes. One participant stated, "It does become more for the baby and the interaction with the other little babies than for yourself." Since previous research findings indicated mothers felt their needs are neglected during the postpartum period (Aston, 2002; Baker et al., 2005), the opportunity to bring babies to the mother and baby yoga classes could be viewed as yet another situation where mothers' needs are overlooked to focus on the care of their baby. Yet the focus on babies may serve as a facilitating mechanism to engage mothers in physical activity which is often deprioritized due to high ethic of care (Gilligan, 1982; Miller \& Brown, 2005).

\section{Community in Class}

The community aspect was an important and significant category for all of the mothers. The mothers described a vibrant network of other mothers that connected through the classes, leading to social support and friendships for many of the women. The physical and emotional parameters created by the teachers enabled the women to view the class as a safe space for themselves and their babies, which provided opportunities to socialize and learn from their fellow mothers. The themes of safe space, shared experience, and mothering resource are discussed below.

Safe Space. There was consensus among all group members that the mother and baby yoga classes were physical and emotional safe havens for themselves and their babies. Three out of the four groups discussed the set-up of the rooms, with all mothers 
in the discussions agreeing on the importance of the environmental space created. The teachers laid out a special carpet on the floor for the mother and baby classes, turned on the ceiling fans for the babies to gaze upon, kept the room warm, and often played soothing music that helped to calm the babies.

Another component of the safe space mentioned by nearly every participant was the feeling of emotional safety the mothers had in the classes. Surprisingly, many of the mothers interviewed expressed the classes were one of the only places they could go without fear or worry about how they were mothering. The idea that women inhabit private spaces while men engage in the public domain is not new in feminist research (Massey, 1994). Yet, the women in this study described this as a novel experience, indicating that their transition to motherhood affected their perception of their place in society. Many of the women described feeling anxious when being out with their babies in public, as they were afraid of how their babies may act. The classes were a place where mothers felt it was "okay for their baby to be a baby," which was a rare feeling when leaving their homes. They described feeling self-conscious and anxious when their babies cried, needed a diaper change, or needed to nurse while in public. One participant indicated she felt more comfortable mothering her baby in the classes than she sometimes did in her own home stating, "I could behave very, very natural, act very natural in classes where there were mamas with the same situation and with their babies." These feelings contributed to the women's belief that the classes were an oasis where they could go and feel supported in the act of mothering:

Just something as simple as being able to stop and feed your baby in the middle of a class. Or if your child is having a fussy day and screaming no 
other moms in the room care that your child is screaming... and it's just really nice to have that support.

The support the women felt from the other mothers in the classes was an instrumental part of the safe space. The participants described the classes as a protected zone where they were free from judgment from other mothers. One mother, for example, stated that class was, "where you can say what you're actually feeling." Several women also expressed the idea that they were among "like-minded" mothers in the classes, which was a different feeling than they had experienced in organized support groups. The feeling of being with like-minded mothers may have provided a buffer from the pressure to be a "good mother" that is ubiquitous in feminist and social research on mothering (Douglas \& Michaels, 2005; Liss \& Erchull, 2012; Medina \& Magnuson, 2009; O’reilly, 2010). Undoubtedly this pressure led to the feelings of anxiety and unease when out in public for many of the women, as they specifically discussed feeling like their babies could not display behaviors that may be indicative of poor parenting, such as crying. Given that most of the participants also expressed feeling that they frequently could not focus their attention on themselves or their babies while at home due to household duties, the importance of this safe space is crucial.

Shared Experience. The feeling of sharing the common experience of new motherhood with their fellow classmates helped mothers normalize and accept their own situations. In terms of their physical experiences, several mothers in every group indicated they felt comforted when doing yoga postures with other mothers. Similar to findings from research by Armstrong and Edwards (2004) on stroller walking exercise interventions for women with postpartum depression, the mothers stated they preferred 
exercising with women in similar situations. One mother described how she imagined she would feel in a regular yoga class stating, "they have no idea why I can't do these things... it just feels more comfortable to be around everyone who's just gone through the same thing." Another mother related that the fun social atmosphere in the class motivated her to exercise:

Well it's the combination of exercising but also having someone lead you and relating just mama to mama ... and you're sitting there in plank pose but then you're laughing about something that somebody's talking about. So it's kind of a way to be exercising but also, "oh this is so hard I don't want to be doing this" but like doing it a little bit more because sometimes exercising wasn't feeling so good or it was challenging. It was just being more fun overall.

Many of the other mothers described the communal atmosphere as a source of fun and companionship, and others indicated that having babies present made the classes more entertaining. These experiences stand in stark contrast to most of the experiences described by the women as they adjusted to motherhood and their postpartum bodies.

One of the features of the yoga classes universally praised by almost every mother interviewed was the "check-in" process. During the beginning of the class the teachers would pose a question or reflection to the group and each woman would take turns answering. Depending on the teacher, or the day, the check-in could be as simple as asking how their day was going, or what a challenge was each mother was experiencing, or something that was going well in their lives. The check-in process gave mothers the opportunity to be heard and to hear from each other, providing a chance to learn about the individuals in the class with them. 
For many of the mothers the check-in was a "powerful" and "cathartic" opportunity that one participant described as a mini-therapy session. The check-in also allowed mothers to compare their situations with others, for many this helped them normalize their mothering experiences and the transition to motherhood. As one participant described, "It makes you realize that there are other people who have gone through the same thing. You're not the only one and that's always I think a really nice feeling."

Some of the most powerful discussions regarding the community created in the classes described the way the classes combatted isolation. An exchange from one of the groups described:

P1: Well it makes you not feel, well you don't feel alone. There's always some of that isolation. In this society you know it's like these little tiny nuclear families that are not really a normal thing. Like moms need other moms. It's not at all normal to be by yourself at a house with a baby.

P2: $\quad$ your husband's gone all day

P3: I definitely like that. You know just getting together with other moms and babies is so crucial for postpartum recovery. Like emotional recovery and just growth as a person and as a mother and as your whole life is changing so much. And like you know a lot of us met in these classes. That's how we met other moms and babies. We go through that process together.

The ability to meet other mothers and create parenting bonds has been connected to improved health outcomes for mothers (Cornell, McCoy, Stampfel, Bonzon, \& Verbiest, 2016), and participation in mothering groups has been connected to increased perception of social support, social capital, and maternal health (Strange, Bremner, Fisher, Howat, \& Wood, 2016). Armstrong and Edwards (2004) found that mothers with 
postpartum depression experienced a decrease in depressive symptomology following a group walking exercise intervention, but they did not find that social support improved for the mothers, which appears to be divergent from the experiences many of the mothers in this study described.

Mothering Resource. The social opportunities and support that women received in the classes extended into several arenas that led the women to view the classes as a mothering resource. Mothers repeatedly described parenting and breastfeeding advice they received from the teachers and other mothers. The check-in time was once again mentioned in this regard, with several mothers describing how they learned helpful tips from other mothers in response to a problem they shared during their check-in. These results were similar to findings by Aston (2002), who found that postpartum women stated they received informational support on mothering more from other mothers in their support groups than the nurses who facilitated the groups.

The opportunity to learn from other mothers and teachers lessened the burden for many of the participants. The mothers described feeling more capable and confident in implementing new strategies with their babies. Contrasting with findings from Aston's study (2002), it did not seem that the mothers interviewed felt overwhelmed or burdened by their peers' suggestions, perhaps because it was optional to seek advice regarding a problem in the first place. One mother described a "take it or leave it" approach to the information shared with her, potentially connected to the supportive atmosphere the students felt the teachers provided. In a meta-analysis of effective postpartum depression prevention interventions Werner and colleagues (2015) theorized that increases in 
mothering efficacy could help to reduce incidences of postpartum depression. The increase in confidence that many of the women experienced through class interactions with teachers and other mothers could help to buffer the mothers against depression.

The classes became a form of social support, which previous studies have shown can help to enable postpartum women to exercise (Connolly et al., 2014; Saligheh et al., 2016) and lead to improved maternal health (Cornell et al., 2016; Strange et al., 2016).

\section{Mamas' Solutions for Mamas}

The final category that emerged from the data was suggestions and ideas the women felt would improve the postpartum experience. The exploration of these issues was an important component in the feminist design of the study that sought to empower and give voice to women's experiences (Beckman, 2014; Choi et al., 2005, Harding, 1987; Lather, 1991; Reinharz, 1992). These conversations were some of the most robust and passionate during the interviews. Some of the women realized that they had not previously examined their individual experiences within a larger context of gender inequity. Others related that participating in the group interview process allowed them to more deeply reflect on their experiences in a way they had not previously. Many of the women had not questioned their realities or looked to possible alternatives for the challenges they faced as new mothers. Conversely, some of the women shared they had felt more aware of these issues since becoming a mother. Interestingly, many of the mothers expressed critiques with the idea of feminism, and how gender equality can apply to the act of mothering. The themes of sociocultural attitudes towards mothers, 
role choice, feminist acceptance, and classes and educational support are discussed below.

Sociocultural Attitudes Towards Mothers. The conversation regarding gender inequity revolved around how the mothers felt in regards to their place in society from institutional and personal perspectives. Nearly all of the women in each group felt that the act of mothering was societally undervalued with implications for postpartum women's feelings of self-worth. Similar to findings from previous research (Aston, 2002; Baker et al., 2005, Zourladani et al., 2011), conversations in all of the groups centered on how many of the women felt less important as mothers than pregnant women. One mother stated, "When you're pregnant, people are helping you out but then postpartum, they're not helping you out anymore. We're overlooked, almost. You did your job, now that's over." The feeling that society does not value motherhood is deeply connected to the mothers' belief that mother and baby yoga classes were isolated safe spaces where they could be a mother, and the importance of the social support they received there. For many the act of breastfeeding was an example of this vulnerability. As one participant described:

As a feminist, I staunchly support the idea of breastfeeding in public, wherever and whenever you want to. You get to feed your baby. But, grappling also with the reality that anytime I expose my breasts in public, it's subject to the male gaze... As much as I'd love to be this army of one in the moment, breastfeeding in public so that I can shift the public's perspective around what this experience is, I'm also grappling with, "okay but do I really want to show my boobs to the 16 year old boy who might objectify me for having them out?" That's been opposing, I guess, feminism and postpartum, for me. 
The ability to breastfeed in the mother and baby yoga classes was discussed in every group as a positive, freeing event. In research conducted by Saligheh and colleagues (2016), many of the participants interviewed mentioned that having exercise classes where they could breastfeed their children would enable them to exercise more effectively. Undoubtedly, the freedom to nurse in class was critical to the success of the mother and baby exercise experience, and also helped to alleviate complicated feelings surrounded nursing in public.

Role Choice. Every woman who participated in this part of the discussion indicated it was extremely important that she have the power to determine the path of her transition to mothering, particularly in regards to work outside the home. As one participant stated, "to me, the feminist side of it is more about giving women the opportunity to do those things and then allowing them to make the choices that feel right for them. And not judging them for those choices." Similar to findings of previous research, many of the mothers acknowledged various social, cultural, occupational, and emotional constraints that limited their choices regarding employment outside of the home (Medina \& Magnuson, 2009).

There were a number of factors that contributed to the mothers' ability to choose to work outside the home including career security, finances, and personal desires. None of the mothers who participated in the study were working full-time while participating in the classes. When considering the discussions regarding the women's feelings of attachment to their babies it is not surprising that many of the women interviewed did not desire to return quickly to full-time work outside the home. One participant grappled 
with the decision to be on the "mommy track" and consequences on her career that would result from choosing to spend time with her children, similar to the "maternal wall" described by Medina and Magnuson (2009) that mothers experienced when working outside the home. For other women the lack of substantial paid family leave policies felt like a limiting factor in their ability to choose when they would return to work. Supported by findings from Salee (2008), family leave policies appeared to greatly impact the changes in family dynamics. Two of the mothers expressed that due to paternal leave their husbands had been able to take on more of the childcare responsibilities in the beginning weeks, helping to establish the fathers' connection to their children and their responsibilities within the household.

The high cost of childcare was also cited by several mothers as the primary consideration in their decision not to work one outside of the home. As one mother stated, "If I were to go back to work, my salary essentially offsets what we would be paying in childcare. Which is absurd, the idea of paying so somebody else can watch my baby and I work, I don't want to do that."

Many of the women who were in financial situations where they felt financially secure in taking extended leave expressed outrage and sadness that other women did not have the ability to make the same choice. As one participant described, "Every milestone she hits I think about how many women have to go work at that point. It's heartbreaking to think that as progressive as we claim to be in our society, this is reality. You have a baby you go back to work." Other women expressed gratitude that they could stay home, 
or had flexible work opportunities that allowed them the ability to work outside the home part-time while also spending a large amount of time with their children.

Feminist Acceptance. One of the most surprising discussions related to the women's conflict around feminism and mothering. This topic had the most inter-group differences and the least intra-group differences. Potentially the women felt less comfortable voicing differing opinions regarding the politicized and charged topic of feminism. For example, within one group interview all of the women discussed whether feminism could relate to parenting as the experiences between genders were so unequal in regards to pregnancy and birth. One mother explained that she felt empowered by pregnancy and birth yet was not sure if that was congruent with feminist ideals of gender equality. Her group then discussed how motherhood related to notions of increased femininity:

P1: I think for myself, as a woman who I've, I've supported myself through my career ... but I have purposefully been more into the femininity that maybe, that I didn't recognize or feel comfortable with before. Because I didn't want, I felt like I had to be tough. I was taking care of myself, living by myself for years and years.

P2: I fully agree with you on that. That's like exactly how I feel.

P3: And how it was for me also.

All of the mothers in this group also expressed that they enjoyed maintaining the house as part of their mothering duties, whereas members of other groups expressed less positive views. The women who more positively portrayed their household responsibilities had a deep sense that they had chosen their new duties and role, while the women who expressed more discontent referred to societal and personal expectations as a cause of 
their new role. One mother directly linked her work in the household sphere to the concept of value and worth. She shared what she described was as an act of feminism in a conversation with her husband:

That struggle was very real when we were first with the child and my husband thought that because I didn't work I didn't have money. And I was like, "That's not the way it works." And we had one conversation about it and it went like this, "You're right. I don't make money. Nobody pays me a paycheck. So now you need to pay me a pay check. I'm your cook. I'm your cleaner. I'm your nanny. I'm your night nurse. And I make way more money than you could possibly ever make." And he said, "You're right." And that was the only conversation we ever had about it. And that to me was exactly what feminism is.

For some women feminism was linked to occupational roles, a participant described her viewpoint regarding her ability to be a mother outside the workforce and a feminist:

I think of myself as a feminist, but not. Because I want to be at home taking care of my children and I feel like the struggle is, is getting to that place where everybody else just agrees that they want to do what they want to do and we're all equal and that's what I think of as feminism.

Other women did not question their ability to be feminist mothers, and believed the act of mothering was inherently empowering. One mother stated, "We birthed babies, we're powerhouses ... it's our resiliency and strength." The varied views of feminism among the mothers often related to whether the women felt they were included in the notion of feminism. Women who shared stories regarding friends who had questioned their exit from the workplace or their mothering techniques were more likely to express that they did not agree with components of feminism.

Classes and Educational Support. The conversations regarding solutions and strategies centered on various kinds of institutionalized support mechanisms, which all of 
the women saw as lacking in their lives. The women envisioned communal living situations, childcare cooperatives, and workplaces that encouraged mothers to bring babies with them to work. Many of the women mentioned a need to increase awareness surrounding postpartum challenges as a means to improve women's experiences and increase women's ability to seek help. At least one participant also related that she felt it would be useful for her male partner to have more education surrounding her needs as a postpartum woman. The women expressed that living in a society with a widespread understanding of postpartum challenges could positively affect new mothers' experiences in public, in the workplace, in their family lives, and in their transition to motherhood.

The idea that postpartum women needed opportunities to be with other postpartum women was universal for all of the mothers interviewed, and is widespread in the literature on postpartum support. Support has been shown to increase exercise adherence, women's feeling of competencies as a mother, and prevent postpartum depression (Aston, 2002; Connolly et al., 2014; Negron et al., 2013; Saligheh et al., 2016). Interacting with other mothers was seen as an important component of postpartum support mechanisms with one mother declaring, "We're just so separated from each other and it's hard. It's not the way that humans are meant to live. So we have these little structures to help us that are crucial because otherwise we'd have nothing ... because we're meant to be together." It is not surprising that every group had members who stated that mother and baby yoga classes should be more accessible and available, as they were an important component of their postpartum support. One group discussed the 
socioeconomic inequities regarding access to postpartum support groups such as mother and baby yoga classes:

It really is a question of privilege. When you think about it, even these groups that I have the opportunity to go to in the middle of the day, to connect with other moms, when I look around in the group, it's largely a lot of white faces. It's a lot of middle to upper-middle class families that are able to partake in these activities to begin with. So I think that question of accessibility is a big one...

It was clear that the women found this component of the interviews stimulating and appreciated the opportunity to share their ideas on how postpartum experiences could be improved for new mothers. They were willing to share deeply personal and challenging experiences around their process of becoming a new mother in part because they viewed it as important work that needed to be done to improve the lives of women.

\section{Discussion and Conclusions}

This is the first study that has explored the experiences of new mothers while exercising with their babies. Results indicate that mother and baby classes can encourage postpartum women to exercise and offer additional support mechanisms for new mothers that had yet to be researched or discussed. Specifically, this study makes clear that mother and baby yoga classes were important resources for the participants, and fulfilled unmet physical, emotional, and informational needs that transcend the typical notion of services provided in an exercise class.

The mothers looked to the classes as a source of healing and guidance for their postpartum bodies more than exercise, as many of the women were unsure and even scared to begin exercising after birth, which is congruent with findings from previous postpartum research (Connelly et al., 2014; Jenkins et al., 2006; Keiffer et al., 2002). In 
an examination of a fitness magazine's recommendations for pregnant and postpartum women, Jette (2006) linked the medicalization of women's pregnancy and exercise experiences with a Foucauldian idea of disciplining women. The notion of an outside expert who holds knowledge was shown to disempower new mothers, yet in this study the mothers described an empowering and liberating experience in the classes. These experiences stemmed from the focus on educating women to confidently perform their own self-care practices and on community sharing that encouraged mother to mother problem solving in the mother and baby yoga classes.

The focus on discussion based sharing through the "check-in" process has not previously been studied in postpartum exercise classes. In a meta-analysis of group versus individual exercise interventions in cancer survivors, Floyd and Moyer (2010) conjectured that group exercise classes might improve quality of life more than individual interventions, yet only if the group classes included activities to foster group relationships. The differing types of social interaction offered to mothers participating in the yoga classes compared to mothers participating in a stroller walking study by Armstrong and Edwards (2004) may somewhat account for the different results regarding social support. Participants in the stroller walking study were depressed, which could have impacted their ability to form connections with other mothers, and social support levels were quantitatively measured which limits comparability to the current study. Results from interviews with postpartum women conducted by Saligheh and colleagues (2016) regarding exercise enablers indicated that the new mothers felt more enthusiastic regarding their discussion-based support groups than postpartum exercise 
classes, yet it appeared the postpartum exercise classes did not contain a discussion component. Saligheh and colleagues (2016) recommended that postpartum exercise groups might be more successful if they included a group discussion, something that was demonstrated in this study. It was clear that the mothers in this study viewed the "checkin" as an important component of their classes. While this format would certainly not appeal to all postpartum women, it may be a useful part of postpartum recovery for many new mothers.

A potential problem with the group sharing was explored in Aston's (2002) study of mothering resource and educational groups conducted by nurses. Aston noted that some women may feel disempowered and hesitant continuing their own mothering practices that might deviate from the other mothers in the group. This is similar to findings that expert status was found to be disempowering to new mothers seeking breastfeeding help in a study conducted by Leeming, Williamson, Johnson, and Little (2015). Utilizing a Foucauldian approach, they highlighted the challenges lactation professionals should consider when counseling women in a "natural" yet challenging act such as nursing. However, in the results from this study the mothers positively described instances where they had learned from other women and where they had taken a role of teacher, highlighting the importance of peer to peer interactions around the act of mothering. These results are similar to Markula's interpretation of Foucault's technology of the self in regards to a mind-body fitness form (2004). As in the classes observed by Markula, the women interviewed discussed their teachers as promoting ethical self-care to a high degree, which helped to build confidence and efficacy in the 
mothers which may potentially help to buffer from postpartum depression (Werner et al., 2015). Previous studies have focused on participation in mothering groups as a means of increasing social support and improving the well-being of mothers (Cornell et al., 2016; Strange et al., 2016), yet this study offered new insights into the ability of an embodied movement practice to help new mothers physically and emotionally recover from birth and motherhood.

Lastly, the findings from this study clarify some of the reasons why women may want to bring their babies to exercise classes. Previously this was presumed to be an issue of access to childcare, yet this study provides more nuanced and complex viewpoints. Certainly some of the mothers did not have access to childcare and therefore could not exercise without their babies, yet many of the mothers explained they did not want to leave their babies even when they had reliable childcare, especially in the first few months postpartum. Previous literature on feminist motherhood offers valid critiques of the social pressures to be a good mother that may lead women to feel they should not want to leave their children (Douglas \& Michaels, 2005; Medina and Magnuson, 2009; O'reilly, 2010). In some instances, the mothers' discomfort at leaving their babies stemmed from anxiety that could be connected to the idea of good motherhood, yet the women interviewed in this current study more frequently discussed feeling judgment and pressure to leave their babies in order to be a good feminist. This interpretation of feminist scholarship may have particularly troubling impacts on the future of gender equality if women feel their mothering choices preclude their acceptance as feminists. 
In summary, the results of this study have shown the potential for exercise classes to provide multiple support services for new mothers including recovery from birth and coping mechanisms for the transformative event of becoming a mother. As most sociocultural institutions disregard the experiences of postpartum women, this study shows that exercise professionals have the potential to significantly improve the lives of this underserved population by offering specifically tailored postpartum classes that allow for the presence of babies and provide for a high degree of interaction between mothers.

Limitations of my study include the selection of participants who attended mother and baby yoga classes, as this would not include women who did not find exercising with other mothers or babies helpful. Another limitation is the relatively homogenous identities of the participants. All of the participants were in heterosexual relationships while taking the classes, most were White, middle-class, college graduates, and all resided in Santa Cruz County. The experiences and perspectives of the participants regarding the postpartum period and the significance of mother and baby yoga classes were influenced by socio-economic, familial, and community factors that might not be present elsewhere.

Future quantitative and qualitative research on the effectiveness of these classes in diverse postpartum populations is warranted, particularly with yoga and other mind-body exercise forms such as Pilates. While there was some heterogeneity in the socioeconomic status and ethnic backgrounds of the participants, cultural issues did not appear to be salient in the women's experiences in the classes in this study. More research regarding the curriculum, design, and inclusion of group sharing processes in postpartum exercise 
classes in diverse populations is also needed. In keeping with many of the women's feelings of ownership over their classes, engaging women in a participatory action research project to design curriculum could be particularly useful. Another component of this research could involve creating mama facilitators to help teach the classes and train additional women, helping to promote and spread awareness and understanding of postpartum issues and support from women themselves. The women in this study desired interaction and help from other mothers, and the interactions they had with other mothers in the classes were some of the most powerful and memorable for them.

Offering mothers the opportunity to become involved in postpartum care could potentially help to bridge the gap that some of the women felt between their realities and the notion of feminism. It was surprising to me that so many of the women I interviewed skeptically viewed the idea that mothers could be feminists, while at the same time they spoke of behaviors and beliefs that seemed to promote feminist ideals of gender equality and empowerment. More research on mothers' perceptions of feminism, including a cross-sectional study that measures cohort effects across multiple generations to compare and contextualize women's perceptions of feminism over time is needed. Additionally, feminist researchers need to continue to bridge the gap into praxis to begin to more fully impact the lives of women.

Given the relative financial security of most of my participants and the community support structures accessible to them, the challenges they experienced as new mothers is alarming and relevant to postpartum medical practitioners and community health centers. As the high numbers of women who experience "baby blues" or 
postpartum depression illustrate, policies and programs that are aimed at postpartum women are not currently providing effective support. It appears the mother and baby yoga classes provided a unique format that was particularly appealing and important for the women I interviewed. The combination of bodily movement in a highly supportive environment with discussion based activities was a particularly effective means to help women cope with the corporeal experience of birth and motherhood. 


\section{References}

Afand, N., Keshavarz, M., Fatemi, N. S., \& Montazeri, A. (2016). Effects of infant massage on state anxiety in mothers of preterm infants prior to hospital discharge. Journal of Clinical Nursing. doi: 10.1111/jocn.13498

Ahearn, E. L. (2006). The pilates method and dance technique: applications in the dance studio. Journal of Dance Education, 6(3), 92-99.

Armitage, N. H., \& Smart, D. A. (2012). Changes in air force fitness measurements preand post-childbirth. Military Medicine, 177(12), 1519-1523.

Armstrong, K., \& Edwards, H. (2004). The effectiveness of a pram-walking exercise programme in reducing depressive symptomatology for postnatal women. International Journal of Nursing Practice, 10(4), 177-194. doi:10.1111/j.1440172X.2004.00478.x

Artal, R., \& O’Toole, M. (2003). Guidelines of the American College of Obstetricians and Gynecologists for exercise during pregnancy and the postpartum period. British Journal of Sports Medicine, 37, 6-12.

Aston, M.L. (2002). Learning to be a normal mother: empowerment and pedagogy in postpartum classes. Public Health Nursing, 19(4), 284-293

Baker, S. R., Choi, P. L., Henshaw, C. A., \& Tree, J. (2005). 'I felt as though I'd been in jail': women's experiences of maternity care during labour, delivery and the immediate postpartum. Feminism \& Psychology, 15(3), 315-342.

Beckman, L.J. (2014). Training in feminist research methodology: doing research on the margins. Women and Therapy, 37(1-2), 164-177. doi: $10.1080 / 02703149.2014 .850347$

Beddoe, A. E., \& Lee, K. A. (2008). Mind-body interventions during pregnancy. Journal of Obstetric, Gynecologic, \& Neonatal Nursing, 37(2), 165-175.

Bellows-Riecken, K. H., Rhodes, R. E. (2008). A birth of inactivity? A review of physical activity and parenthood. Preventive Medicine, 46, 99-110.

Berg, B. L. (2004). A dramaturgical look at interviewing. In B. L. Berg (Ed.), Qualitative research methods for the social sciences (pp. 75-122). Boston: Pearson Education.

Brown, A., Rance, J., \& Bennett P. (2016). Understanding the relationship between breastfeeding and postnatal depression: the role of pain and physical difficulties. Journal of Advanced Nursing 72(2), 273-282. doi: 10.1111/jan.12832 
Buurman, M. B. R, \& Lagro-Janssen, A. L. M. (2013). Women's perception of postpartum pelvic floor dysfunction and their help-seeking behaviour: a qualitative interview study. Scandinavian Journal of Caring Sciences, 27, 406413. doi: 10.1111/j.1471-6712.2012.01044.x

Choi, P., Henshaw, C., Baker, S., \& Tree, J. (2005). Supermum, superwife, supereverything: performing femininity in the transition to motherhood. Journal of Reproductive and Infant Psychology, 23(2), 167-180.

Clark, A., Skouteris, H., Wertheim, E. H., Paxton, S. J., \& Milgrom, J. (2009). My baby body: a qualitative insight into women's body-related experiences and mood during pregnancy and the postpartum. Journal of Reproductive and Infant Psychology, 27(4), 330-345.

Connolly, C.P., Feltz, D.L., \& Pivarnik, J.M. (2014). Overcoming barriers to physical activity during pregnancy and the postpartum period: the potential impact of social support. Kinesiology Review, 3, 135-148. Retrieved from http://dx.doi.org/10.1123/kr.2013-0009

Cornell, A., McCoy, C., Stampfel, C., Bonzon, E., \& Verbiest, S. (2016). Creating new strategies to enhance postpartum health and wellness. Maternal and Child Health Journal, 20(1), 39-42.

Cramp, A. G., \& Bray, S. R. (2010). Postnatal women's feeling state responses to exercise with and without baby. Maternal \& Child Health Journal, 14(3), 343349. doi:10.1007/s10995-009-0462-5

deVault, M. J. (2017). Feminist qualitative research emerging lines of inquiry. In Denzin, N. K., \& Lincoln, Y. S. (Eds.), The Sage Handbook of Qualitative Research $5^{\text {th }}$ ed. (pp 176-194). Thousand Oaks, CA: Sage.

Dale, G. A. (1996). Existential phenomenology: Emphasizing the experience of the athlete in sport psychology research. The Sport Psychologist, 10, 307-321.

Dritsa, M., Da Costa, D., Dupuis, G., Lowensteyn, I., \& Khalifé, S. (2008). Effects of a home-based exercise intervention on fatigue in postpartum depressed women: results of a randomized controlled trial. Annals of Behavioral Medicine, 35(2), 179-187.

Douglas, S., \& Michaels, M. (2005). The mommy myth: The idealization of motherhood and how it has undermined all women. New York, NY: Simon and Schuster.

Eagly, A. H., \& Riger, S. (2014). Feminism and psychology critiques of methods and epistemology. American Psychologist, 69(7), 685-702. Retrieved from http://dx.doi.org/10.1037/a0037372 
Evenson K. R., Aytur S. A., Borodulin K. (2010). Physical activity beliefs, barriers, and enablers among postpartum women. Journal of Women's Health, 18(12), 19251934. doi:10.1089/jwh.2008.1309.

Evenson, K. R., Herring, A. H., \& Wen, F. (2012). Self-reported and objectively measured physical activity among a cohort of postpartum women: the PIN Postpartum Study. Journal of Physical Activity and Health, 9(1), 5-20.

Evenson, K. R., Mottola, M. F., Owe, K. M., Rousham, E. K., \& Brown, W. J. (2014). Summary of international guidelines for physical activity following pregnancy. Obstetrical \& Gynecological Survey, 69(7), 407-414. http://doi.org/10.1097/OGX.0000000000000077

Floyd, A., \& Moyer, A. (2010). Group versus individual exercise interventions for women with breast cancer: a meta-analysis. Health Psychology Review, 4(1), 22 41. doi:10.1080/17437190903384291

Gilligan, C. (1982). In a different voice: Psychological theory and women's development. Cambridge, MA: Harvard University Press.

Gjerdingen, D. K., Froberg, D. G., Chaloner, K. M., \& McGovern, P. M. (1993). Changes in women's physical health during the first postpartum year. Archives of Family Medicine, 2(3), 277.

Gratton, C., \& Jones, I. (2004). Analyzing data II: Qualitative data analysis. In C. Gratton \& I. Jones (Eds.), Research methods for sport studies (pp. 217-227). New York: Routledge.

Harding, S. (1987). Introduction: Is there a feminist method? In S. Harding (Ed.), Feminism and methodology (pp. 1-14). Bloomington IN: Indiana University Press.

Hesse-Biber, S. (2014). A Re-invitation to feminist research. In S. Hesse-Biber (Ed.), Feminist Research Practice: a Primer (pp 1-13). Thousand Oaks, CA: Sage.

Jeffreys, R., \& Nordahl, K. (2002). Preconception, prenatal, and postpartum exercise. Healthy Weight Journal, 16(3), 36.

Jenkins, C., Handcock, P., Burrows, L., \& Hodge, K. (2006). Exercise barriers faced by first-time mothers. New Zealand College of Midwives Journal, 35, 6-11.

Jette, S. (2006). Fit for two? A critical discourse analysis of Oxygen fitness magazine. Sociology of Sport Journal, 23, 331-351.

johnson, j., Butryn, T., \& Masucci, M. A. (2013). A focus group analysis of the US and Canadian female triathletes' knowledge of doping. Sport in Society: Cultures, Commerce, Media, Politics, 1-18. doi:10.1080/17430437.2012.753522 
Kamberelis, G., Dimitriadis, G., \& Welker, A. (2017). Focus group research and/in figured worlds. In Denzin, N. K., \& Lincoln, Y. S. (Eds.), The Sage Handbook of Qualitative Research $5^{\text {th }}$ ed. (pp 692-717). Thousand Oaks, CA: Sage.

Kieffer, E. C., Willis, S. K., Arellano, N. N., \& Guzman, R. R. (2002). Perspectives of pregnant and postpartum Latino women on diabetes, physical activity, and health. Health Education \& Behavior, 29(5), 542-556.

Kitzinger, J. (1994). The methodology of focus groups: the importance of interaction between research participants. Sociology of Health \& Illness, 16(1), 103-121.

Ko, Y., \& Yang, C. (2008). Effects of postpartum exercise program on fatigue and depression during "doing-the-month" period. Journal of Nursing Research (Taiwan Nurses Association), 16(3), 177-185.

Ko, Y., Yang, C., Fang, C., Lee, M., \& Lin, P. (2013). Community-based postpartum exercise program. Journal of Clinical Nursing, 22(15/16), 2122-2131. doi:10.1111/jocn.12117

Larson-Meyer, D. (2003). The effects of regular postpartum exercise on mother and child. International Sportmedicine Journal, 4(6), 1-14.

Lather, P. (1991). Getting smart feminist research and pedagogy with/in the postmodern. New York, NY: Routledge, Chapman and Hall.

Lemming, D., Williamson, I., Johnson, S., Lyttle, S. (2015). Making use of expertise: a qualitative analysis of the experience of breastfeeding support for first-time mothers. Maternal and Child Nutrition, 11, pp. 687-702. doi: 10.1111/mcn.12033

Liss, M., Erchull, M.J. (2012). Feminism and attachment parenting: Attitudes, stereotypes, and misperceptions. Sex Roles 67,131-142. doi: 10.1007/s11199-0120173-z

Martin, A., Horowitz, C., Balbierz, A., \& Howell, E. A. (2014). Views of women and clinicians on postpartum preparation and recovery. Maternal and child health journal, 18(3), 707-713.

Massey. D. (1994). Space, place, and gender. Hoboken, NJ: John Wiley.

McGannon, K. R., \& Schinke, R. J. (2013). "My first choice is to work out at work; then I don't feel bad about my kids": A discursive psychological analysis of motherhood and physical activity participation. Psychology of Sport and Exercise $14,179-188$.

Medina, S., \& Magnuson, S. (2009). Motherhood in the 21st century: implications for counselors. Journal of Counseling \& Development 87, 90-96. 
Miller, Y. D., \& Brown, W. J. (2005). Determinants of active leisure for women with young children - an "ethic of care" prevails. Leisure sciences, 27(5), 405-420.

Miyata, H., \& Kai, I. (2009). Reconsidering evaluation criteria for scientific adequacy in health care research: An integrative framework of quantitative and qualitative criteria. International Journal of Qualitative Research, 8, 64-75.

Montell, F. (1998). Focus group interviews: a new feminist method. NWSA Journal, $11(1), 44-71$.

Munday, J. (2014). Feminist focus groups. In S. Hesse-Biber (Ed.), Feminist Research Practice: a Primer (pp 233-263). Thousand Oaks, CA: Sage.

Negron, R., Martin, A., Almog, M., Balbierz, A., \& Howell, E. A. (2013). Social support during the postpartum period: mothers' views on needs, expectations, and mobilization of support. Maternal and Child Health Journal. (4):616-23. doi: 10.1007/s10995-012-1037-4.

Norman, E., Sherburn, M., Osborne, R. H., \& Galea, M. P. (2010). An exercise and education program improves well-being of new mothers: a randomized controlled trial. Physical Therapy, 90(3), 348-355.

Olesen, V. (2017). Feminist qualitative research in the millenium's first decade. In Denzin, N. K., \& Lincoln, Y. S. (Eds.), The Sage Handbook of Qualitative Research $5^{\text {th }}$ ed. (pp 151-175). Thousand Oaks, CA: Sage.

O'reilly, A. (2010). Outlaw(ing) motherhood: A theory and politic of maternal empowerment for the twenty-first century. Hecate, 36(1/2), 17-29.

O'Shaughnessy, S., \& Krogman, N.T. (2012). A revolution reconsidered? Examining the practice of qualitative research in feminist scholarship. Signs: Journal of Women in Culture and Society, 37(2), 493-520.

Pesce, N. L. (2012, July 30). Moms are slimming down and toning up by doing squats with tots. The New York Daily News. Retrieved from http://www.nydailynews.com

Reinharz, S. (1992). Feminist methods in social research. New York, NY: Oxford University Press.

Righetti-Veltema, M., Bousquet, A., \& Manzano, J. (2003). Impact of postpartum depressive symptoms on mother and her 18-month-old infant. European Child \& Adolescent Psychiatry, 12(2), 75.

Row, M. A., Nevill, A. M., Bellingham-Young, D., Adamson-Macedo, E. N. (2013). Promoting positive postpartum mental health through exercise in ethnically diverse priority groups. Diversity and Equality in Health and Care 10, 185-195. 
Rubin, L.R., Steinberg, J.R. (2011). Self-objectification and pregnancy: are body functionality dimensions protective? Sex Roles 65, 606-618. doi: 10.1007/s11199011-9955-y

Salee, M.W. (2008). A feminist perspective on parental leave policies. Innovations in Higher Education 3, 181-194. doi:10.1007/s10755-007-9049-5

Saligheh, M., McNamara, B., Rooney, R. (2016). Perceived barriers and enablers of physical activity in postpartum women: a qualitative approach. BMC Pregnancy and Childbirth, 16, 131-138. doi: 10.1186/s12884-016-0908-x

Sherman, K., Heard, G., \& Cavanagh, K. (2010). Psychological effects and mediators of a group multi-component program for breast cancer survivors. Journal of Behavioral Medicine, 33(5), 378-391. doi:10.1007/s10865-010-9265-9

Smith, A. \& Sparkes, B.S. (2014). Qualitative research methods in sport, exercise and health: From process to product. New York, NY: Routledge.

Spiteri, G., \& Xuereb, R.B. (2012). Going back to work after childbirth: women's lived experiences. Journal of Reproductive and Infant Psychology, 30(2), 201-216.

Strange, C., Bremner, A., Fisher, C., Howat, P., \& Wood, L. (2016). Mothers' group participation: associations with social capital, social support and mental wellbeing. Journal of Advanced Nursing, 72(1), 85-98.

Taylor, V. (1998). Feminist methodology in social movements research. Qualitative Sociology, 21(4), 357-379.

Tugut, N., Tirkes, D., \& Demeril, G. (2015). Preparedness of pregnant women for childbirth and the postpartum period: Their knowledge and fear. Journal of Obstetrics and Gynaecology, (2015) 35: 336-340. doi:

$10.3109 / 01443615.2014 .960375$

Uden-Kraan, C.F., Chinapaw, M. J. M., Drossaert, C. H. C., Verdonck-de Leeuw, I. M., \& Buffart, L. M. (2013). Cancer patients' experiences with and perceived outcomes of yoga: results from focus groups. Support Care Cancer (2013) 21:1861-1870. doi:10.1007/s00520-013-1728-4

Van Puymbroeck, M., Burk, B. N., Shinew, K. J., Kuhlenschmidt, M. C., Schmid, A. A. (2011). Perceived health benefits from yoga among breast cancer survivors. American Journal of Health Promotion 27(5), 308-315.

Werner, E., Miller, M., Osborne, L. M., Kuzava, S., \& Monk, C. (2015). Preventing postpartum depression: review and recommendations. Archives of women's mental health, 18(1), 41-60. 
Woolhouse, H., Perlen, S., Gartland, D., \& Brown, S. J. (2012). Physical health and recovery in the first 18 months postpartum: Does cesarean section reduce longterm morbidity? Birth: Issues in Perinatal Care, 39(3), 221-229. doi:10.1111/j.1523-536X.2012.00551.x

Zourladani, A., Tsaloglidou, A., Tzetzis, G., Tsorbatzoudis, C., \& Matziari, A. (2011). Low impact exercise and well-being in Greek postpartum women. International SportMed Journal, 12(1), 30-38. 


\section{CHAPTER 3: CONCLUSION}

The postpartum time period is a time of contradictory experiences for many women as they adjust to the demands of motherhood and recover from the physical and emotional changes that accompany pregnancy and birth (Aston, 2002; Baker et al, 2005). Mother and baby yoga classes are growing in popularity, particularly in urban areas, as new mothers seek social and informational support to help them adjust and cope (Pesce, 2010). Results from previous studies have shown mother and baby exercise classes are effective (Cramp \& Bray, 2010; Norman et al., 2010) and researchers have recommended future research on these types of interventions (Saligheh et al., 2016); yet there was no previous inquiry into the experiences of women in mother and baby exercise classes of any type. As postpartum women have reported feeling overlooked and neglected by medical and institutional policies (Aston, 2002; Baker et al, 2005; Choi et al, 2005), this study sought to critically examine and determine the ability of exercise classes to address women's physical and emotional needs while babies were present.

A feminist methodological approach and analysis, while rare in conventional exercise research approaches, is a necessary component of research that seeks to examine the experiences of postpartum women. This study illustrates that postpartum women often feel insignificant and discarded by their communities and support structures, leading women to seek support in unexpected avenues. The mother and baby yoga classes provided many avenues of support to postpartum women that reached far beyond what would be expected in a typical exercise class. The stories and experiences shared by the mothers in this study demonstrate a need for exercise professionals to consider 
how crucial postpartum support is needed by new mothers, and how they can tailor exercise interventions to fill that void. 


\section{APPENDIX A}

\section{THEMATIC DATA ANALYSIS}

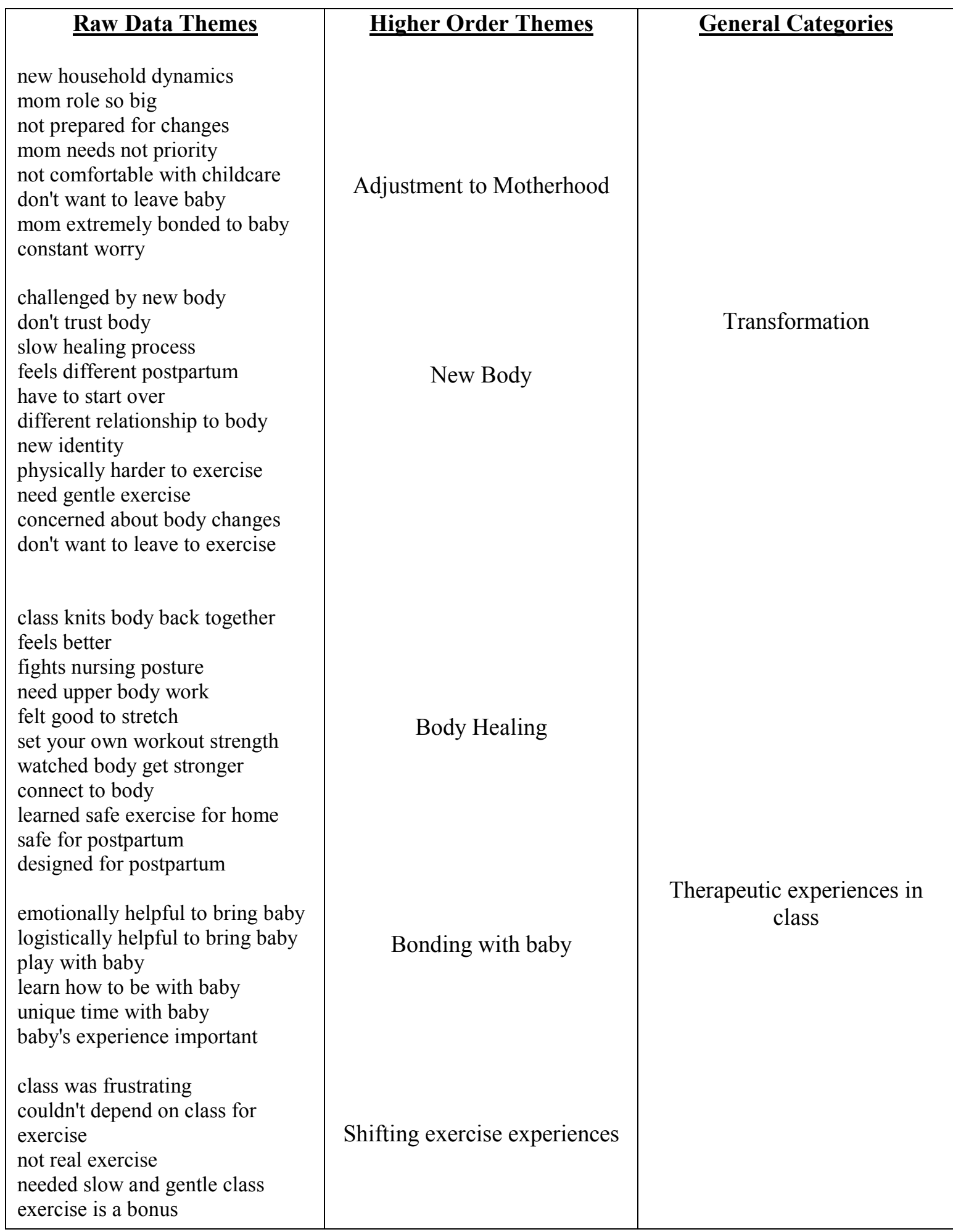




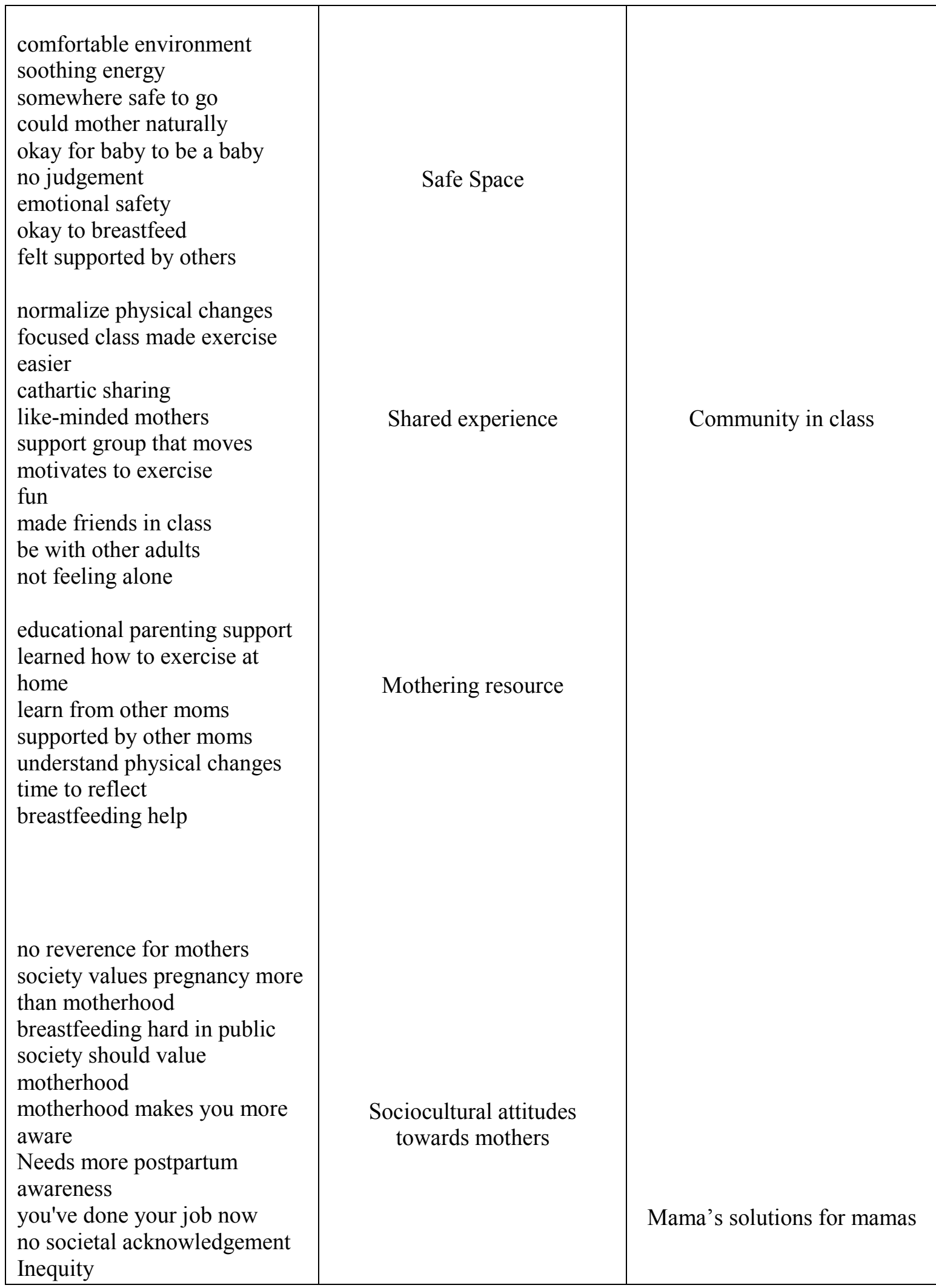




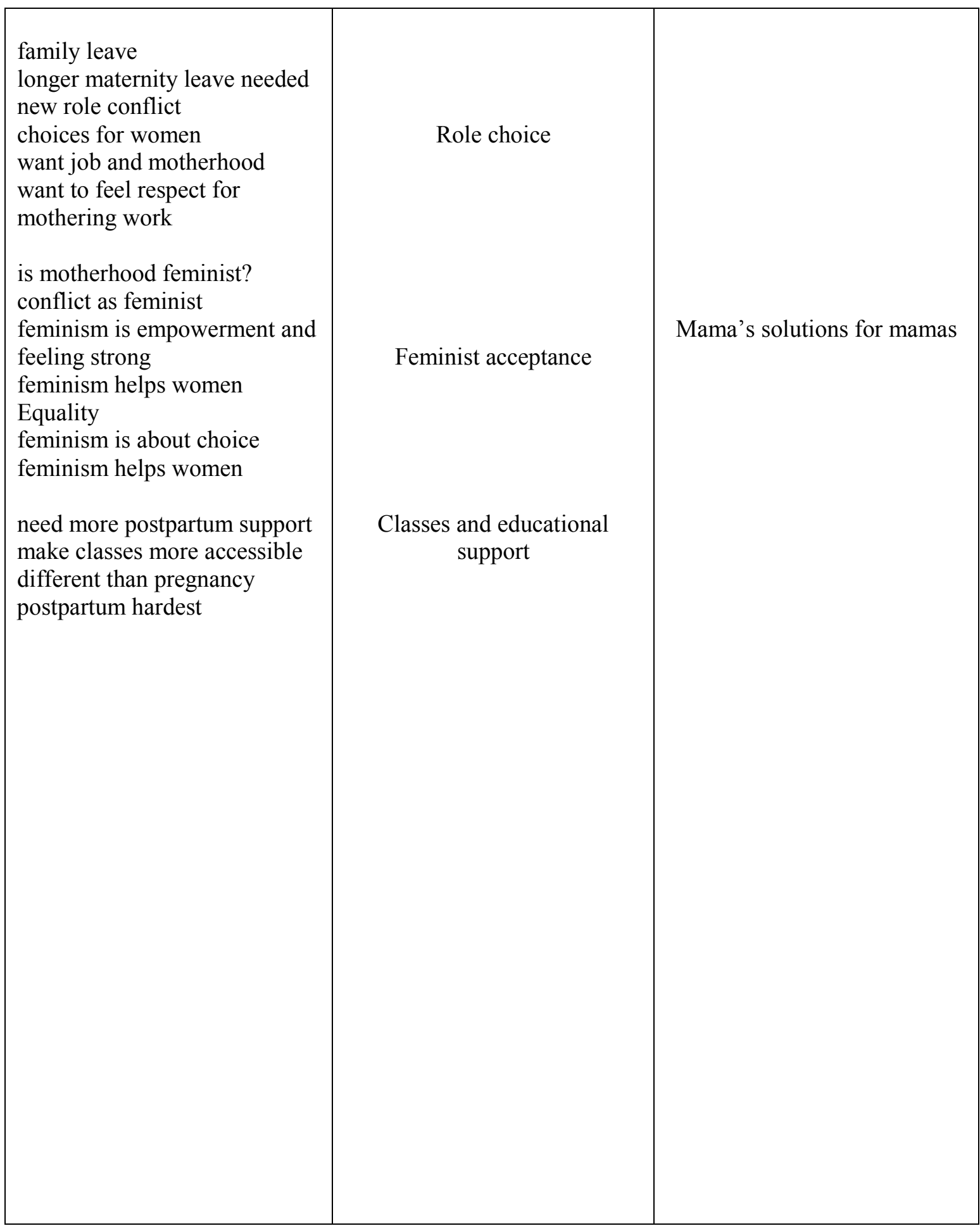




\section{APPENDIX B}

\section{INTERVIEW GUIDE}

\section{Icebreaker Beginning Activity:}

Make a list of all the words that you think of when I say the word motherhood. You have 1 minute to write them down.

Make a list of all the words that you think of when you hear the word postpartum.

Make a list of all the words that you think of when you hear the word feminism.

\section{Questions:}

1. How do you feel about exercising since becoming a mother?

2. What does it feel like to exercise with your baby in the mom/baby classes?

a. Probe: What are the challenges?

3. What does it feel like to exercise with other new moms in the classes?

a. Probe: Can you talk about in what ways other moms were/are part of your social support/network?

4. What aspects of the classes were the most helpful to you?

a. Probe: What aspects were the least helpful?

5. What are the experiences of your body since giving birth?

6. What are the challenges you have had as a new mother?

a. Probe: Motherhood as women's problems or shared by the family?

b. Probe: What supports you in your role as a mother?

Transition: We've talked about your experience with exercise and motherhood, now I would like to transition to some broader topics regarding your postpartum experiences

7. We have talked about your experiences as a woman. Feminist research deals with the experiences of women. My study is a feminist analysis of women's experiences with postpartum exercise with babies present. For you, what does the word feminism mean as it relates to exercise with your babies present during the postpartum period? 
a. Probe: Are there any particular institutions or policies which have (or have not) helped you since your baby was born?

8. What changes would you like to see in how we as a society treat the postpartum experiences of women?

9. Anything else you would like to add?

10. What was this interview like for you, talking about this? 


\section{APPENDIX C}

\section{INFORMED CONSENT FORM}

\section{AGREEMENT TO PARTICIPATE IN RESEARCH}

Responsible Researchers: Dr. Ted Butryn and Ky Russell, Department of Kinesiology, San Jose State University

Title of Protocol: An Analysis of the Experiences of Postpartum Women in Mother and Baby Yoga Classes

1. You have been asked to participate in a research study investigating the impact of yoga classes with babies present on the postpartum period.

2. You will be asked to participate in a group interview with the researcher and other postpartum women regarding your experience with postpartum pilates and yoga classes with babies present. This interview may last between 60-90 minutes. The interview will be audio recorded, but will only be utilized by the researchers.

3. No actual names to individual identification codes will be associated with the participants in this study. Names will be changed during the transcription of the interviews to protect the identity of the participant.

4. There are no anticipated risks associated with participation in this study.

5. Although the results of this study may be published, no information that could identify you will be included. You will be referred to only by a coded name.

6. There will be no compensation for participation in this study.

7. Questions about this research may be addressed to the primary researcher, Ky Russell (415) 902-5868 or Dr. Ted Butryn, at (408) 924-3068. Complaints about the research may be presented to Dr. Matthew Masucci, Chair of the Department of Kinesiology, at (408) 924-3020. Questions about research subjects' rights to research-related injury may be presented to Pamela Stacks, Ph. D., Associate Vice President of Graduate Studies and Research, at (408) 924-2427.

8. No service of any kind, to which you are otherwise entitled will be lost or jeopardized if you choose to "not participate" in the study. 
9. Your consent is being given voluntarily. You may refuse to participate in the entire study or in any part of the study. You have the right to not answer questions you do not wish to answer. If you decide to participate in the study, you are free to withdraw at any time without any negative effect on your relations with San Jose State University to with any other participating institution or agency.

10. At the time you sign this consent form, you will receive a copy of it for your records, signed and dated by the researcher.

\section{Signatures}

"I have read the above statements, and by signing and dating my name above the researcher's name and date, I am giving my consent for the researcher to use my information for the benefit of the study."

Participant's Signature

Date

Researcher's Signature

Date

- The signature of the subject on this document indicates agreement to participate in this study.

- The signature of the researcher in this document indicates agreement to include the above names subject in the research and attestation that the subject has been fully informed of his or her rights. 